\title{
As startups no ordenamento jurídico: uma leitura comparada dos ecossistemas de startups na Argentina, no Chile e no Brasil
}

\author{
Ingrid Iana Matos Anunciação ${ }^{1}$ \\ Gabriela Andrade Fernandes ${ }^{2}$
}

\begin{abstract}
Resumo: Este artigo tem como objetivo buscar possíveis soluções para os obstáculos legislativos e culturais que as startups enfrentam no Brasil, por meio de uma na álise teórica e comparada dos institutos jurídicos e costumes empresariais dos ecossistemas jurídicos em que as empresas de caráter inovador argentinas e chilenas estão inseridas. Pretende, também, evidenciar a necessidade de modernização das legislações que influenciam na dinâmica das startups, bem como de estimular o fomento e o auxílio governamental às atividades empresariais inovadoras de pequeno e médio porte no Brasil, além de apresentar os principais conceitos caracterizadores dessas empresas, sua dinâmica e importância no cenário empresarial globalizado.
\end{abstract}

Palavras-chave: Startups. Globalização. Brasil. Argentina. Chile.

\section{The startups in the legal system: a comparative reading of startups ecosystems in Argentina, Chile and Brazil}

\begin{abstract}
This paper aims to seek possible solutions to the legislative and cultural obstacles that startups face in Brazil, based on a theoretical and comparative analysis of the legal institutes and business customs of the legal ecosystems in which Argentine and Chilean companies of an innovative character are inserted. Also, to highlight the need to modernize the laws that influence the dynamics of startups, as well as the promotion and government assistance to small and medium sized innovative business activities in Brazil, in addition to presenting the main concepts that characterize these companies, their dynamics and their importance in the globalized business scenario.
\end{abstract}

Keywords: Startups. Globalization. Brazil. Argentina. Chile.

\section{Introdução}

O presente artigo tem o escopo de analisar as startups e seu ecossistema, principalmente na Argentina, Chile e Brasil, no âmbito das transformações e adequações jurídicas provocadas pela globalização e pelos avanços do Direito Empresarial, sobretudo no que tange aos aspectos favoráveis e desfavoráveis das legislações desses países.

\footnotetext{
${ }^{1}$ Pós-graduanda em Relações Sociais e Novos Direitos, linha de pesquisa Direito Empresarial e Globalização, pela Universidade Estadual do Sudoeste da Bahia (UESB). Bacharela em Direito pela Universidade Estadual do Sudoeste da Bahia (UESB). E-mail: ingridiana.ma@gmail.com.

${ }^{2}$ Doutora em Memória: Linguagem e Sociedade na Universidade Estadual do Sudoeste da Bahia (UESB). Mestre em Administração pela Universidade Federal da Bahia (UFBA). Graduada em Direito pela Universidade Estadual de Santa Cruz (UESC). Membro do grupo de Pesquisa em Análise de Discurso (GPADis/CNPq/UESB). Professora adjunta do Curso de Direito da Universidade Estadual do Sudoeste da Bahia (UESB), campus Vitória da Conquista. E-mail: gabriela.conquista@gmail.com.
} 
A pesquisa foi desenvolvida por meio de uma análise teórica e comparada dos institutos jurídicos e costumes empresariais aplicáveis às startups da Argentina, Chile e Brasil. O estudo comparado auxilia no processo de construção do conhecimento, sendo, portanto, fundamental para trazer a objetividade científica necessária ao tema (SCHNEIDER; SCHMITT,1998). Nessa perspectiva, foram analisadas as disposições legais existentes em legislações, costumes empresariais, bem como dados oficiais de organizações especializadas sobre o assunto, para verificar o direcionamento específico de cada sistema jurídico voltado ao incentivo de empresas inovadoras de pequeno e médio portes, com base nas seguintes categorias: 1) flexibilização e redução de burocracias nos procedimentos de abertura e encerramento de empresas; 2) adequação de tipos societários ao mercado de inovação; 3) incentivos e benefícios fiscais voltados às startups; 4) simplificação em procedimentos administrativos quando da recuperação de empresas; 5) programas governamentais direcionados ao fomento da atividade empresarial do tipo startup.

O presente artigo está estruturado em três seções. A primeira conceitua as startups, apresenta suas características e a função de modelo de negócio representado por elas. A segunda seção discute as iniciativas de fomento à atividade empresarial de pequeno e médio portes nas legislações da Argentina, Chile e Brasil e de que maneira elas abarcam e regulam as startups. Por fim, a última seção trabalha com a análise comparativa dos institutos jurídicos apresentados na seção anterior e avalia aspectos favoráveis e desfavoráveis das legislações de cada país.

As considerações finais ratificam os pressupostos deste trabalho, no sentido de que existe a necessidade de modernização das legislações que influenciam na dinâmica das startups, bem como de fomento e auxílio governamental às atividades empresariais inovadoras de pequeno e médio portes no Brasil. Desse modo, com o objetivo de proporcionar segurança jurídica aos empreendimentos com características de inovação, é imperiosa uma análise comparada de institutos jurídicos internacionais, como os da Argentina e do Chile, por exemplo, para uma melhor reflexão acerca do ambiente regulatório nacional. Por fim, as referências que serviram de suporte teórico e metodológico para as análises e discussões neste trabalho são apresentadas na última seção.

\section{Delineando as startups}

As startups ganham cada dia mais espaço no mercado empresarial mundial e brasileiro. Elas são dinâmicas, ágeis, flexíveis, com potencial de crescimento rápido e rentável, assumem altos riscos e inovam de forma disruptiva.

Não existe um conceito formado do que é startup, a expressão, em tradução livre, significa partida, início. Contudo, as definições giram em torno da escalabilidade e repetibilidade em um modelo disruptivo, que opera em condições de elevada incerteza no mercado. O termo ganhou força no fim dos anos 1990, durante a primeira "bolha da internet" e tem influência direta do Vale do Silício, na Califórnia, Estados Unidos da América (EUA).

Em tempos de crise econômica mundial, as startups surgiram como alternativa para aproveitar oportunidades, com a experimentação e a diversificação de produtos e mercados. Umbilicalmente relacionadas ao desenvolvimento de tecnologia e internet, elas têm o objetivo de resolver problemas, criar 
produtos e/ou atribuir mais funcionalidade aos que já existem, além de impor um ritmo diferente para o tradicional mercado empresarial (SANTOS, 2016).

Com base nessa perspectiva, urge salientar que essas empresas necessitam de uma blindagem jurídica mais específica, não só para regular costumes e práticas frequentes no mercado internacional, mas também propiciar um cenário confortável para investimentos, tendo em vista o elevado risco intrínseco ao negócio.

O estudo jurídico a respeito das startups no Brasil é algo relativamente novo, pois existem particularidades que lhes são inerentes e não são contempladas no modelo empresarial tradicionalmente desenvolvido no país. Por essa razão, houve a necessidade de recorrer a fontes primárias e secundárias, tais como sites, blogs, canais de notícias, matérias jornalísticas de estudiosos e especialistas da área etc., para embasar o entendimento sobre o tema.

Ademais, a escassez de produção jurídica aprofundada, combinada com a regulamentação recente, e o alto grau de incerteza das startups demonstraram a necessidade de uma análise de institutos jurídicos internacionais, com vista à aferição do ambiente regulatório dessas empresas, de modo que se possa refletir acerca dos anseios e necessidades de empreendedores de pequeno e médio portes, sobretudo no que tange à segurança jurídica dessa modalidade de empreendimento.

Nesse panorama, as regras jurídicas de um país podem ser definidoras para o sucesso de uma startup. Portanto, se elaboradas com o objetivo de acompanhar a evolução rápida dessas empresas, elas desempenham papel essencial no desenvolvimento econômico e social. Por outro lado, se o sistema de regras jurídicas de determinada localidade for mal estruturado pode se tornar um limitador de seu crescimento econômico e do estímulo à inovação.

Em 2018, a Startup Genome (2017) publicou uma pesquisa mundial intitulada Global Startup Ecosystem Report ${ }^{3}$, a qual restou demonstrado que as startups movimentaram mais de US\$140 bilhões só em 2017. Diante da potencialidade do crescimento mercadológico das startups, em especial no Brasil, torna-se imperativo discutir a adequação do ordenamento pátrio para abarcar empresas inovadoras, ou seja, a necessidade de complementação e expansão do ambiente regulatório, tanto para o fomento das iniciativas em curso quanto para o surgimento de outras, condição que permitirá às startups brasileiras competir internacionalmente sem deixar de lado a segurança jurídica.

Para compreender melhor o contexto de surgimento das startups, é importante retornar aos EUA pós-Segunda Guerra Mundial (1939-1945), momento em que a pesquisa e a gestão dentro das universidades tiveram que se reinventar e buscar novas fontes de financiamento, devido ao direcionamento de recursos federais para a Guerra. As aludidas pesquisas passaram a contar com

\footnotetext{
${ }^{3}$ O Startup Genome examinou como as cidades ajudam a crescer e sustentar ecossistemas de startups vibrantes mediante oito fatores principais: financiamento, alcance de mercado, conexão global, talento técnico, experiência em startups, atração de recursos, envolvimento corporativo, ambição e estratégia de fundadores. O Startup Genome avaliou 55 ecossistemas de startups em 28 países e revela informações de mais de 10.000 startups (STARTUP GENOME, 2017).
} 
investimentos oriundos de investidores particulares, chamados de "capital de desenvolvimento". Atualmente esses investidores equivalem aos denominados venture capital ${ }^{4}$ (FALCÃO, 2017).

É dentro desse contexto de inovação e de extrema incerteza que o termo startup surge pela primeira vez. Refere-se, portanto, a empresas emergentes ou iniciantes e que geralmente estão em fase de pesquisa e desenvolvimento.

Apesar de não haver um conceito formado do que é uma startup, Ries (2012), autor da obra Lean Startup (Startup Enxuta), adota uma concepção bastante conhecida pelos especialistas: "Uma startup é uma instituição humana projetada para criar novos produtos e serviços sob condições de extrema incerteza" (RIES, 2012, p. 26). Dessa forma, para Ries (2012), a startup preenche três requisitos básicos e fundamentais: precisa ser inovadora, empreendedora e trabalhar em situação de incerteza.

Por outro lado, em The startup owner's manual (startup: manual do empreendedor), Blank (2014) leciona que “[...] startup é uma organização temporária construída para buscar respostas que promovam a obtenção de um modelo de negócio repetível e escalável” (BLANK, p. 28).

A Associação Brasileira de Startups (2017) também tem sua definição:

Startups são empresas em fase inicial que desenvolvem produtos ou serviços inovadores com potencial de rápido crescimento. Ser startup é um momento na vida de uma empresa, onde uma equipe busca desenvolver um produto/serviço inovador, de base tecnológica, que tenha um modelo de negócio facilmente replicado e possível de escalar sem aumento proporcional em seus custos. Dentre as principais características que diferenciam e definem uma startup, destacam-se: Inovação, Escalabilidade, Repetibilidade, Flexibilidade e Rapidez (ABSTARTUPS, 2017, online).

Em 01 de junho de 2021 foi sancionada a Lei Complementar no 182/2021, que estabelece o Marco Legal das Startups e, no seu artigo $4^{\circ}$, define: "São enquadradas como startups as organizações empresariais ou societárias, nascentes ou em operação recente, cuja atuação caracteriza-se pela inovação aplicada a modelo de negócios ou a produtos ou serviços ofertados” (BRASIL, 2021).

Da análise dessas definições, vislumbramos que a diferença primordial entre uma empresa tradicional e uma startup está na forma de operação da atividade empresarial. Nesse sentido, as startups são empresas, cujo objetivo essencial é atingir um modelo de negócio escalável e repetível, operando em condições de elevada incerteza no mercado, enquanto empresas tradicionais avaliam e minimizam riscos ao trabalhar com planos de negócios pautados em produtos e mercados já conhecidos. Desse modo, há uma nítida distinção entre elas. As startups diferenciam-se das empresas tradicionais desde a fase de idealização até o modo de operacionalizar e escalonar sua abrangência.

Nessa senda, o blog de empreendedorismo e inovação, Semente (2018), ensina:

O funcionamento de uma startup está baseado no mindset de teste de hipóteses e o mantra de "errar rápido e barato". Estar em constante interação com o mercado em

\footnotetext{
4 “Venture capital, capital empreendedor ou capital inteligente é uma modalidade de investimento na qual investidores aplicam recursos em empresas com expectativas de rápido crescimento e elevada rentabilidade. Este investimento acontece por meio da aquisição de ações ou direitos de participação. Esta forma de operação, diferente de um financiamento, implica, além da entrada de recursos financeiros, em um compartilhamento de gestão do investidor com o empreendedor." (CODEMEC, 2014, online).
} 
busca de feedbacks que possam tornar mais eficazes e eficientes o desenvolvimento da solução acelera a validação do negócio (SEMENTE, 2018, online).

Portanto, é válido ressaltar que o ambiente em que a startup se insere está em constante mudança e o erro não é sinônimo de falha, muito pelo contrário, é sinal de que o caminho para o sucesso está mais palpável. Por essa razão, as empresas desse modelo de mercado impõem rotinas de erros programados, justamente para fomentar a criação de produtos e serviços.

Nesse diapasão, existem diversos conceitos que demonstram a singularidade das startups no ambiente empresarial mundial, seja pelo seu alto potencial econômico, seja por sua dinâmica inovadora disruptiva ${ }^{5}$. Independentemente do motivo, entender e proteger essas empresas é essencial. Com tal percepção, uma regulamentação jurídica adequada traz segurança para o negócio e maior potencial de crescimento.

É no contexto de grandes inovações tecnológicas e empreendedoras que as legislações do mundo inteiro vêm-se adequando para receber empresas com características de startup, de modo que a adaptação dos sistemas jurídicos e legislativos a esse modelo empresarial inovador torna-se fundamental para uma dinâmica econômica e social globalizada e integrada.

\section{Panorama das startups}

As startups têm uma modalidade de negócio fundamentada na lógica de lean production ou lean enterprise $e^{6}$ a qual, segundo alguns estudiosos, tem inspiração japonesa, tendo em vista os princípios organizacionais do just in time ${ }^{7}$, qualidade total, processo de melhoramento contínuo, equipes autônomas de produção e uma série de instrumentos que implementam todos esses conceitos e teorias (FARIA, 2018).

Essas empresas representam atualmente a elite do empreendedorismo global. No imaginário comum, o termo startup sempre está conectado a empresas de alta tecnologia, com a capacidade de implementar grande quantidade de inovações em modos de produzir e organizar negócios, além de conquistar mercados, criar produtos e serviços.

O Vale do Silício é o maior centro de formação de empresas startup do mundo. Segundo dados da pesquisa publicada pela Global Startup Ecosystem Report 2017 (STARTUP GENOME, 2018), do total de investimentos realizados nessas empresas, cerca de $28 \%$ são destinados àquela região, a qual concentra US\$ 268 bilhões em valor circulante, seguida de Nova Iorque e Londres, que reúnem os montantes de US\$ 71 bilhões e US\$ 44 bilhões, respectivamente.

Concomitante ao crescimento continuado, e diante das perspectivas do mercado, também ocorrem mudanças fundamentais com relação à economia e aos ramos de atuação dos modelos de

\footnotetext{
${ }^{5}$ Inovação disruptiva ocorre quando se implanta um novo conceito no mercado em uma determinada indústria. São inovações que introduzem novos benefícios ao mercado, com a pretensão de ser mais simples e conveniente aos usuários, muitas vezes, oferecendo um produto com menor custo (ABSTARTUPS, 2018, online).

${ }^{6}$ Tradução livre: produção enxuta ou empresa enxuta.

${ }^{7}$ Uma das características do sistema de produção de mercadorias do Toyotismo, no qual se produz somente o necessário, no tempo necessário e na quantidade necessária.
} 
negócio. Se, por um lado, empresas de primeira e segunda geração de ecossistemas de inicialização global - mídias sociais, mídias e outras empresas de internet puras - estão em declínio, por outro, empresas de tecnologias proeminentes tendem a transformar não só o que já é realizado via internet, mas também (e diretamente) setores essenciais para a sociedade, entre eles, transporte, saúde, manufatura pesada e agricultura. $\mathrm{Na}$ terceira onda, a perspectiva é de desenvolvimento e aprendizado para o mundo real com laços marcantes e intrínsecos à indústria (STARTUP GENOME, 2018).

Os polos com maior movimentação de capital voltado para startups do mundo são conhecidos como ecossistemas. Esses locais concentram condições ideais para o florescimento de iniciativas empresariais inovadoras, visto que neles estão presentes empreendedores, profissionais habilitados, tecnologia qualificada, altos investimentos e estruturas urbanas capazes de sediar fisicamente empresas e pessoas.

Além de proporcionar toda a estrutura técnico-físico, esses ambientes são responsáveis por capacitar os indivíduos por meio de programas de treinamento, eventos de networking e consultoria especializada, de maneira que podem ser considerados berçários para startups (FARIA, 2018), além de se tornarem vitrines para investidores de risco.

Ademais, governos ao redor do mundo começaram a reconhecer o valor da inovação, dos empregos e das receitas advindas de novos empreendedores e negócios, de modo que começaram a modificar as estruturas legislativas, bem como a se movimentar culturalmente, em prol do empreendedorismo de pequenas e médias empresas com características inovadoras.

A exemplo da importância dos ecossistemas de startups para as economias mundiais, é válido ressaltar os ecossistemas dos países que compõem o BRICS ${ }^{8}$. Na Rússia, o mercado de startups está diretamente ligado ao crescimento dos gastos domésticos em pesquisa científica e desenvolvimento. Os trabalhos de projeto experimental com investimento totalizam 1,1\% do PIB nacional (NANGS, 2019). A Índia tem o terceiro maior ecossistema de startups do mundo, hospeda cerca de 7.500 startups e mais de 21 unicórnios, de acordo com o relatório Indian Tech Startup Ecosystem: Approaching Escape Velocity (2018) (NASSCOM, 2018). Nesse contexto de grandes ecossistemas, de acordo com a CB Insights (2020), a China registra 110 empresas com avaliações bilionárias e empresas como Alibaba e Xiaomi já deixaram de ser unicórnios e são decácornios, pois valem mais de US\$10 bi. A África do Sul sai como uma das apostas até 2035 na corrida tecnológica, de acordo com o Fórum da Nova Economia Bloomberg (2019), juntamente com a Índia e a China, estas duas últimas com grandes chances de superar os Estados Unidos. $\mathrm{Na}$ referida pesquisa, $73 \%$ dos entrevistados acreditam que o país africano será um dos centros de inovação tecnológica do mundo.

Nesse panorama, legislações podem ser definidoras para o sucesso de uma startup, tendo em vista que um sistema de regras jurídicas mal estruturadas pode se tornar um limitador para o estímulo à inovação e ao crescimento econômico. Por outro lado, se elaborado com o objetivo de acompanhar a

\footnotetext{
8 BRICS é um agrupamento de países de mercado emergente em relação ao seu desenvolvimento econômico formado por Brasil, Rússia, Índia, China e África do Sul.
} 
evolução rápida dessas empresas, desempenha papel essencial no desenvolvimento econômico e social da localidade à qual pertence.

A grande dificuldade das leis, no entanto, está na velocidade das transformações resultantes da tecnologia, do mundo dinâmico e globalizado. Um ambiente regulatório saudável requer diálogo entre a sociedade civil e seus órgãos reguladores. Boas legislações se antecipam e acompanham as mudanças da sociedade, proporcionando condições para que os negócios floresçam e impulsionem a economia.

O Doing Business é uma das principais publicações anuais do Banco Mundial, cuja finalidade é analisar leis e regulamentos que facilitam ou dificultam as atividades de empresas em economias diversas e, ao final, apresentar a pontuação de 190 países no ranking sobre facilidade para fazer negócios. Em 2019, a pesquisa apontou 314 reformas regulatórias, no período entre 2 de junho de 2017 e $1^{\circ}$ de maio de 2018. Em nível global, 128 economias introduziram reformas regulatórias em todas as áreas analisadas (THE WORLD BANK, 2019).

Nessa perspectiva, países da América Latina começaram a implementar sistemas com o intuito de favorecer a criação, a manutenção e a dissolução de empresas com características de startups, em contrapartida, com a diminuição da carga tributária e, em alguns casos, isenções e mecanismos de fomento da atividade empresarial, tal como ocorre com as legislações da Argentina e do Chile.

A criação de leis baseadas nas características essenciais às startups sinaliza a importância jurídica e econômica destas para a sociedade. Pautada nesse entendimento, a legislação se volta a esse modelo de negócio de forma a tornar o ambiente regulatório mais seguro e apto para receber mais investimentos.

Desse modo, as economias classificadas com maior facilidade em fazer negócios não são as que não dispõem de regulamentação, mas aquelas nas quais existem mecanismos facilitadores de interação do mercado sem dificultar desnecessariamente o desenvolvimento do setor empresarial (THE WORLD BANK, 2019). As inovações trazidas pelas legislações argentina e chilena demonstram que não há necessidade de grandes modificações nos institutos jurídicos de um país para incentivar a atividade empresarial, basta um olhar cauteloso para as principais dificuldades enfrentadas pelas empresas.

À medida que as legislações impactam positivamente a economia e o ecossistema empreendedor de nações como a Argentina e o Chile, elas passam a ter importância no cenário da inovação. Nesse contexto, o Brasil possui desafios institucionais e culturais a superar, principalmente quando é necessário englobar governos municipais, estaduais e federal em redes voltadas para o fomento do empreendedorismo.

Desse modo, comparar as economias latino-americanas do Chile e da Argentina visando compreender o funcionamento, a dinâmica e os componentes atuantes desses mercados, revela-se de fundamental importância, pois assim é possível identificar possíveis soluções para o Brasil, voltadas à flexibilização do ordenamento jurídico pátrio no tocante à atuação de empresas inovadoras, como é o caso das startups, por exemplo. Para tanto, as regras direcionadas a esse segmento deverão ser adequadas às suas necessidades e peculiaridades, e isso inclui acompanhar a constante inovação e quebrar paradigmas, características tão comuns a esse setor. 


\section{Ecossistema empreendedor da Argentina, do Chile e do Brasil: uma análise comparativa}

A modernização é o pilar para a construção de um ambiente regulatório adequado para empresas de inovação com características de startups no Brasil. O país não tem um ambiente regulatório propício para o empreendedorismo, haja vista o grande número de procedimentos burocráticos e entraves legislativos. Devido ao processo de globalização em que o país está inserido, o desenvolvimento econômico está cada vez mais relacionado a inovações tecnológicas, asseguradas por ambientes regulatórios flexíveis, e preparado para as adversidades (RAMOS; MATOS, 2018).

Assim, nesta pesquisa, as principais necessidades identificadas para o ecossistema das startups foram: flexibilização e redução de burocracias nos procedimentos de abertura e encerramento de empresas; adequação de tipos societários do mercado de inovação; incentivos e benefícios fiscais voltados às startups; simplificação de procedimentos administrativos quando da recuperação de empresas; e programas governamentais voltados para o fomento de atividade empresarial do tipo startup.

Portanto, mesmo sem esses facilitadores, mas tendo em vista que o Brasil é considerado uma das maiores economias globais, avaliada com US\$ 2,14 trilhões pelo Fundo Monetário Internacional (FMI, 2018) ${ }^{9}$, a promoção de mecanismos voltados para o empreendedorismo auxiliará ainda mais o país na sua capacidade de competir internacionalmente. Diante disso, voltar o olhar para outros países com boas práticas é uma das maneiras para incentivar o mercado interno a promover o fortalecimento $\mathrm{e}$ desenvolvimento de pequenas e médias empresas com características inovadoras e, por conseguinte, alcançar evidência internacional.

Conforme se afirmou anteriormente, o Brasil sancionou o Marco Legal das Startups e Empreendedorismo Inovador - Lei Complementar $n^{\circ}$ 182/2021 - com a finalidade de atrair investidores, abrir oportunidades e incentivar o empreendedorismo inovador (BRASIL, 2021). A legislação é fruto da compilação de regulamentações voltadas para as startups e inspiradas em boas práticas internacionais, como as da Argentina e do Chile. Apesar de recente, a conquista deixou o universo empreendedor brasileiro otimista (GOV, 2021).

A burocracia nos procedimentos de regularização é pauta recorrente entre empreendedores brasileiros. Diante da complexidade de abertura e fechamento de negócios, processo que dura, em média 79,5 dias (THE WORLD BANK, 2017), o Brasil não está bem colocado nos rankings de competitividade (RAMOS; MATOS, 2018). Esses são, pois, entraves que desencorajam o surgimento de empresas.

Em direção contrária, a Argentina e o Chile, por meio de mecanismos para auxiliar os empreendedores na abertura de seus negócios, desburocratizaram processos e simplificaram procedimentos. Ao aprovar a Ley de Empresa en 1 día, ou seja, a criação on-line de empresas em um dia, o governo chileno trouxe um incentivo para a constituição de pequenas e médias empresas e, consequentemente, para o desenvolvimento do mercado empresarial daquele país, que tem demonstrado estar em constante crescimento (SEBRAE, 2014, online). Nesse cenário, se pode notar que países não

\footnotetext{
${ }^{9}$ O Brasil ocupa a nona posição da lista de países com as maiores economias do mundo. Liderada pelos EUA, a lista é divulgada todos os anos pelo Fundo Monetário Internacional por meio do Fórum Econômico Mundial.
} 
precisam abrir mão da segurança jurídica de seus procedimentos, basta criar ferramentas tecnológicas para simplificar seus processos de abertura e fechamento de empresas.

Devido à morosidade desses processos no Brasil, as startups, normalmente, utilizam da figura do Microempreendedor Individual (MEI) ${ }^{10}$ para evitar a burocracia, porque o MEI já é constituído por meio de ferramenta on-line, menos burocrática, o que reduz, consideravelmente, o tempo despendido para a formalização de uma empresa, necessitando apenas da ampliação desse procedimento aos demais tipos societários ${ }^{11}$.

Todavia, o aludido instituto não consegue abarcar grande parte das startups, além disso, torna-se obsoleto em pouco tempo e já não atende à característica da escalabilidade, tendo em vista que o limite máximo de faturamento anual é baixo, no máximo $\mathrm{R} \$$ 81.000,00 (oitenta e um mil reais), condição que, no futuro, enseja modificação da sociedade empresarial e insatisfação do empreendedor.

Para solucionar problemas levantados pelos empreendedores, é necessário identificar os obstáculos e criar mecanismos com vistas a incentivar à atividade empresarial. Diante disso, os principais óbices aos atores de startups são: burocratização de processos de abertura e encerramento de empresas; modificação de tipo societário; alta carga tributária; falta de incentivo fiscal e ambiente culturalmente desfavorável à promoção da atividade inovadora (STARTSE, 2017).

Nessa toada, construímos tabelas comparativas com o objetivo de facilitar a visualização de alguns desses obstáculos, bem como dos mecanismos utilizados na Argentina, Chile e Brasil, analisando suas vantagens e/ou desvantagens.

Tabela 1 - Flexibilização e redução de burocracias nos procedimentos de abertura e encerramento de empresas

\begin{tabular}{|l|l|l|l|}
\cline { 2 - 4 } \multicolumn{1}{c|}{} & \multicolumn{1}{c|}{ Argentina } & \multicolumn{1}{c|}{ Chile } & \multicolumn{1}{c|}{ Brasil } \\
\hline Mecanismo & Lei das PyMEs & Lei de Empresa em 1 día & $\begin{array}{l}\text { Lei Complementar n } \\
\text { 128/2008 (MEI); LTDA; } \\
\text { Lei de S/A }\end{array}$ \\
\hline $\begin{array}{l}\text { Tempo de } \\
\text { formalização de uma } \\
\text { empresa }\end{array}$ & 1 dia & 1 dia & 79,5 dias \\
\hline Registro on-line & Sim & Sim & Apenas para o MEI \\
\hline $\begin{array}{l}\text { Exigências } \\
\text { documentais }\end{array}$ & $\begin{array}{l}\text { Simplificado para } \\
\text { pequenas e médias } \\
\text { empresas }\end{array}$ & $\begin{array}{l}\text { Simplificado para } \\
\text { pequenas e médias } \\
\text { empresas }\end{array}$ & $\begin{array}{l}\text { Simplificado apenas } \\
\text { empresários individuais } \\
\text { enquadrados como MEI. } \\
\text { Não alcança sociedades } \\
\text { empresariais }\end{array}$ \\
\hline
\end{tabular}

Fonte: Ramos; Matos, 2018; Sebrae, 2014; The World Bank, 2017.

Além disso, a facilidade em fazer negócios na Argentina melhorou. Duas leis regulatórias foram essenciais para a constituição de novos negócios. As simplificações e modificações advindas da Lei das

${ }^{10}$ Lei Complementar n ${ }^{\circ} 123$, art. 18-A, $\$ 1^{\circ}$ : Considera-se MEI o empresário individual que exerça atividades de industrialização, comercialização e prestação de serviços no âmbito rural, que tenha auferido receita bruta, no ano calendário anteior, de até 81.000,00 e que seja optante do Simples Nacional, além de não esteja impedido de optar pela sistemática prevista neste artigo (BRASIL, 2006, online).

11 É válido ressaltar que, em 10/10/2018, foi sancionada a Lei da Desburocratização, Lei 13.726/2018, que tem como objetivo simplificar atos e procedimentos administrativos da Administração Pública, o que pode interferir no tempo de formalização de uma empresa no país, contudo, ainda não existem dados que comprovem tal afirmação. 
PyMEs e da Lei dos Empreendedores trouxeram algumas facilidades: abertura e fechamento de empresas, enquadramento fiscal, acesso a investimentos, ao capital, a incentivos tributários e fiscais.

Tabela 2 - Adequação de tipos societários ao mercado de inovação

\begin{tabular}{|c|c|c|c|}
\hline & Argentina & Chile & Brasil \\
\hline Mecanismo & $\begin{array}{l}\text { Lei PyMEs/Lei dos } \\
\text { Empreendedores }\end{array}$ & Lei de Empresa em 1 dia & Lei do MEI \\
\hline Objetivos & $\begin{array}{l}\text { Simplificação no } \\
\text { processo de abertura e } \\
\text { encerramento de } \\
\text { empresas. } \\
\text { Enquadramento Fiscal. } \\
\text { Facilidades no acesso à } \\
\text { capital e incentivos ao } \\
\text { investimento. Criação } \\
\text { de formatos de } \\
\text { sociedade empresarial. }\end{array}$ & $\begin{array}{l}\text { Simplifica a criação, } \\
\text { modificação, } \\
\text { transformação, fusão, } \\
\text { cisão, extinção e } \\
\text { dissolução de empresas. }\end{array}$ & $\begin{array}{l}\text { Facilitar a } \\
\text { formalização da } \\
\text { atividade de } \\
\text { pequenos } \\
\text { empreendedores } \\
\text { individuais. }\end{array}$ \\
\hline Vantagens/Desvantagens & $\begin{array}{l}\text { Voltado para pequenas } \\
\text { e médias empresas. }\end{array}$ & $\begin{array}{l}\text { Aplicável aos principais } \\
\text { tipos de sociedade: } \\
\text { responsabilidade LTDA, } \\
\text { corporação fechada, } \\
\text { anônima e coletiva } \\
\text { comercial. }\end{array}$ & $\begin{array}{c}\text { Apenas para } \\
\text { empresas com } \\
\text { faturamento anual } \\
\text { inferior a } \mathrm{R} \$ \\
81.000,00 .\end{array}$ \\
\hline
\end{tabular}

Fonte: Ramos; Matos, 2018; Endeavor Brasil, 2017.

No contexto da tributação, a Argentina simplificou o processo administrativo de aferição e pagamento de impostos, os quais tiveram os prazos de pagamento ampliados. No Brasil, o Simples Nacional é um facilitador, contudo, não alcança sociedades mais complexas, a exemplo das sociedades anônimas, mesmo que elas se enquadrem no teto do faturamento das pequenas e médias empresas ${ }^{12}$.

A alteração nos tributos argentinos também proporcionou incentivo ao investimento, com a redução do imposto de renda em até 10\% dos investimentos realizados pela empresa. A ideia é similar à Lei do Bem ${ }^{13}$ brasileira, no entanto, na Argentina, o incentivo é para pequenas e médias empresas, no Brasil, restringe-se a empresas optantes do regime de apuração do Lucro Real, isto é, a Lei do Bem é voltada para grandes empresas. Há muito tempo, o empresariado brasileiro tem reivindicado incentivos reais para empresas de pequeno e médio porte e o Marco Legal das Startups promete modernizar o ambiente de negócios no país para despertar a atenção de investidores, sem necessitar de participação do capital social da empresa (RAMOS; MATOS, 2018; GOV, 2021).

12 Art. 3-: Consideram-se microempresas ou empresas de pequeno porte, a sociedade empresária, a sociedade simples, a empresa individual de responsabilidade limitada e o empresário a que se refere o art. 966 da Lei no 10.406 , de 10/01/2002 (Código Civil), devidamente registrados no Registro de Empresas Mercantis ou no Registro Civil de Pessoas Jurídicas, conforme o caso, desde que: I - no caso da microempresa, aufira, em cada ano-calendário, receita bruta igual ou inferior a $\mathrm{R} \$ 360.000,00$ (trezentos e sessenta mil reais); II - no caso de empresa de pequeno porte, aufira, em cada ano-calendário, receita bruta superior a $\mathrm{R} \$ 360.000,00$ (trezentos e sessenta mil reais) e igual ou inferior a $\mathrm{R} \$ 4.800 .000,00$ (quatro milhões e oitocentos mil reais) (BRASIL, 2006, online).

13 A Lei no 11.196/05, ou Lei do Bem, cria a concessão de incentivos fiscais às pessoas jurídicas que realizarem pesquisa e desenvolvimento de inovação tecnológica. 
Tabela 3 - Incentivos e benefícios fiscais voltados às startups

\begin{tabular}{|c|c|c|c|}
\hline & \\
\hline & Argentina & Chile & Brasil \\
\hline Mecanismo & Lei das PyMES & $\begin{array}{cc}\text { Lei da Empresa em } & 1 \\
\text { dia } & \\
\end{array}$ & $\begin{array}{l}\text { Lei Complementar } \mathrm{n}^{\circ} \\
123 \text { - Simples Nacional }\end{array}$ \\
\hline Incentivos e Benefícios & $\begin{array}{c}\text { Dedução } 10 \% \text { do IR; } \\
\text { Crédito Fiscal IVA } \\
\text { (similar ao ICMS) a pagar } \\
\text { a partir dos } \\
\text { investimentos; Emissão } \\
\text { de Nota Fiscal após o } \\
\text { pagamento. }\end{array}$ & $\begin{array}{c}\text { Registro em papel fiscal } \\
\text { único. }\end{array}$ & $\begin{array}{c}\text { Regime único de } \\
\text { arrecadação, inclusive de } \\
\text { obrigações acessórias. }\end{array}$ \\
\hline
\end{tabular}

Fonte: RAMOS; MATOS (2018).

Para Ramos e Matos (2018), o modelo ideal de tributação para as startups deve ser baseado na simplificação e no incentivo. A simplificação, segundo os autores, significa legislar sobre tributos de maneira transparente e facilitar o seu recolhimento. $\mathrm{O}$ incentivo significa criar tributos específicos para as startups, analisando as características intrínsecas ao negócio, o que resultaria na diminuição do peso das fases iniciais e no crescimento dessas empresas.

Além disso, as alterações legislativas na Argentina e no Chile simplificaram os procedimentos administrativos de recuperação de empresas, incentivaram a renegociação da dívida de pessoa física, criaram mecanismos para reabilitação de empresas viáveis, agilizaram procedimentos e deixaram todo o processo mais transparente com a utilização de plataformas eletrônicas, sem custo de atualização diária e disponível para todo o público (DESTINO NEGÓCIO, 2019).

Tais facilitadores auxiliam na formalização dos encerramentos dos negócios e proporcionam maior segurança aos investidores, empreendedores, trabalhadores e todo o mercado internacional. Isso não significa que os riscos inexistem, porém eles podem ser minimizados caso a empresa não dê certo. A ideia de segurança jurídica para startups que não alcançam o resultado almejado é de extrema importância, se se levar em consideração o alto o índice de mortalidade dessas empresas no Brasil (FDC, 2012).

Ademais, o Brasil possui mecanismos para incentivar pesquisa, desenvolvimento e inovação por meio da proteção da propriedade intelectual, mas suas aplicações ainda carecem de melhorias. Com relação à legislação de propriedade intelectual, os maiores problemas elencados pelos empreendedores são a morosidade no tempo de finalização da legalização de patentes, marcas e afins, e a dificuldade com os procedimentos (VIEIRA, 2017). A Confederação Nacional da Indústria (CNI, 2014) mostra que a deficiência na estrutura do Instituto Nacional da Propriedade Industrial (INPI) prejudica a indústria e a inovação brasileira. Uma atitude comum nesse contexto é os inventores e mentes criativas terem preferência por lugares mais propícios à regulamentação das suas invenções.

Para Ramos e Matos (2018), o investimento em pessoal qualificado e o uso de tecnologia são alternativas para superar o problema da morosidade nos procedimentos de regularização de marcas, patentes e similares. Além disso, os autores defendem o uso de inteligência artificial e tecnologias para digitalizar e automatizar etapas visando maior produtividade do INPI.

A respeito dos aspectos regulatórios do ambiente tecnológico, ao qual as startups estão submetidas, é importante destacar que o Brasil tem buscado se adequar às inovações internacionais. $\mathrm{O}$ 
Marco Civil da Internet, a Lei de Proteção de Dados e a Lei da Informática e, mais recentemente, o Marco Legal das Startups, são exemplos de legislações atuais que estão presentes no dia a dia das startups e auxiliam no desenvolvimento seguro da empresa. A legislação específica para o fomento da atividade empresarial na qual a startup se insere é uma grande vitória para os empreendedores, pois significa uma oportunidade para alavancar os negócios, bem como fazer com que o Brasil desburocratize o ambiente empreendedor.

Para além do ambiente regulatório, os mecanismos de fomento à atividade das startups devem, também, ser analisados. O Chile e a Argentina desenvolvem programas voltados à promoção da atividade empresarial de startups como, por exemplo, os programas Start-Up Chile e Buenos Aires Academy Emprende.

No Chile, o programa é utilizado para motivar empreendedores a se instalarem no país, fomentar a atividade de startups e promover o encontro de investidores e startups. O Start-Up Chile e a legislação facilitada para pequenos e médios empresários impactam positivamente a economia e o ecossistema empreendedor chileno, razão pela qual o país ocupa lugar de destaque internacional em empreendedorismo. Na Argentina, mais especificamente na cidade de Buenos Aires, o programa Buenos Aires Academy Emprende promove a organização de setores que integram o sistema e demonstra o engajamento do governo local para fomentar a atividade empresarial da região.

No Brasil, também já foram introduzidas boas práticas como essas, como é o caso do programa Start-Up Brasil:

[...] que incorporou em seu processo de seleção aceleradoras privadas que trouxeram aporte financeiro adicional ao investimento feito pelo governo federal, além de espaço de trabalho, mentoria e atividades de acesso ao mercado aos proponentes dos projetos apoiados com bolsas de CNPq. Essas bolsas, por sua vez, tiveram seus valores revisados de acordo com o mercado de trabalho no setor. A experiência profissional não acadêmica também foi valorizada tanto quanto a científica para fins de obtenção de bolsas de maior valor (RAMOS; MATOS, 2018, p. 27).

país:

Vide abaixo, de forma sintética a análise comparativa dos programas governamentais de cada

Tabela 4 - Programas governamentais voltados para o fomento de atividade empresarial do tipo startups

\begin{tabular}{|c|c|c|c|}
\hline & Argentina & Chile & Brasil \\
\hline Mecanismos & Buenos Aires Academy Emprende & Start-Up Chile & Start-Up Brasil \\
\hline $\begin{array}{l}\text { Vantagens/Desv } \\
\text { antagens }\end{array}$ & $\begin{array}{l}\text { Organiza diversos setores que } \\
\text { integram o sistema, com o escopo } \\
\text { de incentivar a atividade de } \\
\text { startups. } \\
\text { Funciona em Buenos Aires e está } \\
\text { em processo de expansão para } \\
\text { outras localidades. }\end{array}$ & $\begin{array}{l}\text { Motiva } \\
\text { empreendedore } \\
\text { s estrangeiros a } \\
\text { se instalarem no } \\
\text { país, fomenta a } \\
\text { atividade de } \\
\text { startup, } \\
\text { promove } \\
\text { encontro entre } \\
\text { investidores e } \\
\text { startups em } \\
\text { todo o país. }\end{array}$ & $\begin{array}{l}\text { Seleção de aceleradoras } \\
\text { privadas para aporte } \\
\text { financeiro adicional ao } \\
\text { investimento feito pelo } \\
\text { governo federal. } \\
\text { Espaço de trabalho, } \\
\text { mentoria e atividades de } \\
\text { acesso ao mercado aos } \\
\text { proponentes dos projetos } \\
\text { apoiados com bolsas de } \\
\text { CNPq. } \\
\text { Ainda não ganhou força. }\end{array}$ \\
\hline
\end{tabular}

Fonte: RAMOS; MATOS (2018); MOED (2018). 
Tal como o Marco Civil da Internet e o Marco Legal da Ciência e Tecnologia, o Marco Legal das Startups é de iniciativa da sociedade civil, tem a finalidade de modernizar o ecossistema para empresas inovadoras e propõe medidas para reconhecer e simplificar os obstáculos do ambiente regulatório brasileiro que dificultam o desenvolvimento de novos empreendimentos em tecnologia, por meio de um ambiente regulatório experimental denominado sandbox, cujas principais características são menos burocracia e mais flexibilidade para lançar serviços e produtos (RAMOS; MATOS, 2018; GOV., 2021).

Desse modo, o Marco Legal das Startups auxiliará na remoção dos obstáculos que os empreendedores incluem no rol de complicadores para o desenvolvimento da atividade empresarial no Brasil. Um Marco Legal discutido pelos principais atores do ecossistema empresarial, que buscam nas legislações estrangeiras as melhores práticas voltadas ao crescimento e fortalecimento das startups, é primordial não só para o país despontar como uma potência internacional em empresas de inovação, mas também para evitar a saída de empreendedores com ideias brilhantes para procurar incentivos fora.

Além disso, a criação do ambiente regulatório pautado na segurança jurídica e nos anseios da sociedade civil favorece o desenvolvimento econômico e social de segmentos empresariais impossibilitados de competir em igualdade de condições com grandes empresas. Portanto, identificar as dificuldades do ecossistema em relação às startups, estudar o tratamento destinado a essas empresas em outros países e adaptar o sistema jurídico brasileiro, com vistas a impulsionar a atividade empresarial de pequeno e médio portes, são ações que, efetivamente, demonstrarão ao mundo que o Brasil tem condições reais de se tornar uma economia segura, competitiva e participativa com as suas startups.

\section{Considerações finais}

Em todo o mundo, as startups ganham, cada vez mais, espaço no mercado empresarial. Em tempos de crise econômica mundial, elas surgiram (e surgirão) como alternativa e oportunidades para experimentação e diversificação de produtos e mercados.

O papel do Direito Empresarial é proporcionar um ambiente favorável ao desenvolvimento das startups, facilitar a sua competitividade nos mercados interno e externo, dar suporte ao fomento dessas atividades, bem como auxiliar na segurança jurídica, sem desconsiderar as características essenciais do negócio: versatilidade e crescimento exponencial.

As startups têm grande potencial e importância nas localidades em que se inserem, em virtude da sua capacidade de promover o desenvolvimento econômico. Nesta pesquisa, constatou-se que o sistema regulatório brasileiro não tem fomentado a inovação e o empreendedorismo no país, em particular, devido às suas características: leis empresariais rígidas quanto ao modo de constituição e encerramento de empresas; burocracia e lentidão na constituição de empresas, assim como na concessão de patentes, quando comparado a outros países; poucos e inexpressíveis benefícios fiscais; ausência de tipos societários mais flexíveis ao modelo das startups e de programas governamentais de incentivo e apoio ao empreendedorismo de startups. No entanto, com o advento do Marco Legal das Startups, a perspectiva é de melhora e maior fomento ao ecossistema, inclusive para startups que apresentem soluções inovadoras ao próprio governo. 
A Argentina e o Chile se mostraram, em nossa pesquisa comparativa, mercados econômicos favoráveis ao empreendedorismo digital, exatamente porque investiram em um sistema regulatório flexível e dinâmico, com vistas ao fomento do mercado empresarial, razão pela qual despontaram como nações atrativas aos investimentos de capital nesse segmento. Esses países perceberam a movimentação internacional e implementaram em seus sistemas jurídicos facilitadores tributários, auxílios legislativos para criação, manutenção e dissolução de empresas, incentivos fiscais e mecanismos de estímulo, com o objetivo primordial de impulsionar as startups.

Desse modo, durante a construção analítica deste trabalho, notamos que o Brasil está atrasado em relação a outras nações quando o assunto são empresas com características de startups, sobretudo porque nos deparamos com uma cultura legislativa empresarial pautada, principalmente, na rigidez dos institutos. $\mathrm{Na}$ apresentação dos resultados desta pesquisa, por meio de tabelas comparativas, visualizamos os mecanismos utilizados nos ecossistemas da Argentina, Chile e Brasil, no que concerne às formas de incentivos para o mercado empreendedor, seja com base em legislações flexíveis e modernas, seja por meio de programas de fomento à atividade empresarial do tipo startup.

Contudo, insta salientar que, com a sanção da Lei Complementar no 182/2021, o legislativo brasileiro demonstra interesse no fomento à criação de empresas inovadoras no seu modelo de negócio, produto ou serviço, com um ambiente regulatório que visa impulsionar o mercado e possibilita maior visibilidade internacional ao Brasil, além de impedir a saída de profissionais da área, registro e utilização de ideias brasileiras em outros países devido a entraves legislativos e burocráticos no INPI.

Apesar dos entraves legais identificados neste trabalho, o ecossistema de startup brasileiro está em plena expansão. Àqueles que participam diretamente deste mercado, cabe, portanto, apontar as dificuldades e auxiliar na construção de um ambiente jurídico seguro e favorável à sua consolidação, de forma a conduzir o Brasil a alcançar patamares ainda maiores.

\section{Referências}

ABSTARTUPS. Associação Brasileira de Startups. ACCENTURE. Radiografia do Ecossistema Brasileiro de Startups. 2017.

ABSTARTUPS. Associação Brasileira de Startups. Inovação, distupção e mesmice. Publicado em: 07.2018. Disponível em: <https://abstartups.com.br/2018/07/04/inovacaodisruptiva/>. Acesso em: 08.03.2019.

AGÊNCIA CÂMARA NOTÍCIAS. Proposta estabelece medidas para estimular a criação de startups. Publicado em: 04.2019. Disponível em: <https://www.camara.leg.br/noticias/626494-PROPOSTAESTABELECE-MEDIDAS-PARA-ESTIMULAR-A-CRIACAO-DE-STARTUPS>. Acesso em: 16.04.2020

\section{BLANK, Steve. Startup: Manual do Empreendedor o guia passo a passo para construir uma} grande companhia. Rio de Janeiro: Alta Books, 2014.

BRASIL, Lei Complementar $\mathrm{n}^{\circ} 182$ de $1^{\circ}$ de junho de 2021. Institui o marco legal das startups e do empreendedorismo inovador. Disponível em: <https://www.in.gov.br/en/web/dou/-/leicomplementar-n-182-de-1-de-junho-de-2021-323558527>. Acesso em 10.06.2021. 
BRASIL, Lei Complementar no 123 de 14 de dezembro de 2006. Institui o Estatuto Nacional da Microempresa e da Empresa de Pequeno Porte. Disponível em: < http://www.planalto.gov.br/ccivil_03/leis/lcp/lcp123.htm>. Acesso em 29.05.2020.

CB INSIGHTS. The Complete List Of Unicorn Companies. Disponível em: <https://www.cbinsights.com/research-unicorn-companies>. Acesso em 10.06.2021.

CNI. Confederação Nacional da Indústria. Propriedade intelectual: as mudanças na indústria e a nova agenda. Brasília: CNI, 2014. 87 p.: il. - (Propostas da indústria eleições 2014; v. 39).

CODEMEC. O que é venture capital. Publicado em: 22.04.2014. Disponível em: <http://codemec.org.br/geral/o-que-e-venture-capital/>. Acesso em: 11.03.2019.

DESTINO NEGÓCIO. Lei chilena facilita para que endividados não precisem fechar uma empresa. Disponível em: < https://destinonegocio.com/br/empreendedorismo/lei-chilena-facilita-paraque-endividados-nao-precisem-fechar-uma-empresa/>. Acesso em: 08.03.2019.

ENDEAVOR BRASIL. Vale do Silício: como fazer parte, mesmo não estando lá. Publicado em: 28.11.2017. Disponível em: <https://endeavor.org.br/inovacao/vale-do-silicio/>. Acesso em: 05.02.2019.

FALCÃO, João Pontual de Arruda. Startup Law Brasil: o direito brasileiro rege, mas desconhece as startups. 2017. 160 f. Dissertação (Mestrado) - Curso de Direito. Escola de Direito do Rio de Janeiro. Fundação Getúlio Vargas. Rio de Janeiro. 2017.

FARIA, Louise Scoz Pasteur de. O poder dos sonhos: uma etnografia de empresas startup no Brasil e no Reino Unido. Tese (Doutorado) - Universidade Federal do Rio Grande do Sul. Instituto de Filosofia e Ciências Humanas. Pós-Graduação em Antropologia Social. Porto Alegre. 2018.

FDC. Fundação Dom Cabral. Causas da mortalidade de startups brasileiras. 2012.

Fórum da Nova Economia Bloomberg. Pesquisa Bloomberg: China e Índia serão centros de inovação tecnológica até 2035. Publicado em: 09.2019. Disponível em: <

https:/ / www.bloomberg.com.br/blog/pesquisa-bloomberg-china-e-india-serao-centros-de-inovacaotecnologica-ate-2035/>. Acesso em: 10.06.2021.

GOV - GOVERNO DO BRASIL. Marco Legal das Startups modernizará ambiente de negócios brasileiro. Publicado em: 06.2021. Disponível em: < https://www.gov.br/pt-br/noticias/financasimpostos-e-gestao-publica/2021/06/marco-legal-das-startups-modernizara-ambiente-de-negociosbrasileiro >. Acesso em: 10.06.2021.

GRAHAM, Paul. Startup = Growth. Publicado em: 09.2012. Disponível em: <http:/ / paulgraham.com/growth.html>. Acesso em: 11.03.2019.

MOED, Jonathan. Forbes. “Start-Up Chile's Impact 2010-2018: Inside The Revolutionary Startup Accelerator”. Publicado em: 19.11.2018. Disponível em: <https://www.forbes.com/sites/jonathanmoed/2018/11/19/start-up-chiles-impact-2010-2018-insidethe-revolutionary-startup-accelerator/\#1a87c09b6dc5>. Acesso em: 25.02.2019.

NANGS. PWC \& RVC: Visão geral da indústria russa de capital de risco "MoneyTree". Publicado em: 09.2019. Disponível em: < https://nangs.org/analytics/pwc-rvk-obzor-venchurnoj-industrii-rossiimoneytree-navigator-venchurnogo-rynka-za-2018-god-i-pervoe-polugodie-2019-goda-pdf $>$. Acesso em 10.06.2021. 
NASSCOM. Indian Tech Start-Up Ecosystem 2018: Approaching Escape Velocity. Disponível em: $<$ https://nasscom.in/knowledge-center/publications/indian-tech-start-ecosystem-2018-approachingescape-velocity>. Acesso em 10.06.2021.

RAMOS, Pedro; MATOS, Felipe. Manual de boas práticas em políticas públicas de apoio a startups. Coleção Dínamo Playbooks. Disponível em: <https://hotsite-

dinamo.azurewebsites.net//storage/chapters/OmqekDwhqcys9qbsoLMI4Y1sv6IpJ74704rD59TZ.pdf>. Acesso em: 11.11.2018.

RIES, Eric. A startup enxuta: como os empreendedores atuais utilizam a inovação contínua para criar empresas extremamente bem-sucedidas. [tradução Texto Editores]. São Paulo: Lua de Papel, 2012.

SANTOS, Iara Rodrigues dos. O lado jurídico das startups: empreendedorismo, inovação e responsabilidade social. 2016. 46 f. TCC (Graduação) - Curso de Direito, Faculdade de Direito, Universidade Federal de Juiz de Fora, Juiz de Fora, 2016.

SCHNEIDER, Sergio; SCHIMITT, Cláudia Job. O uso do método comparativo nas Ciências Sociais. Cadernos de Sociologia, Porto Alegre, v. 9, p. 49-87, 1998.

SEBRAE. Observatório Internacional Sebrae: Argentina. Publicado em: 2014. Disponível em: $<$ http://ois.sebrae.com.br/pais/argentina/>. Acesso em: 20.02.2019.

SEBRAE. Observatório Internacional Sebrae: Chile. Publicado em: 2014. Disponível em: <http://ois.sebrae.com.br/pais/chile/>. Acesso em: 22.02.2019.

SEMENTE. Startup: saiba se você tem uma. Publicado em 07.05.2018. Disponível em: <http://blog.sementenegocios.com.br/definicao-de-startup/>. Acesso em 12.02.2019.

STARTSE. Censo StartSe 2017. Brazil Startup Ecosystem Report. Brazil.2017. Disponível em: $<$ http://lp.startse.com.br/wp-content/uploads/2018/06/2.2-fintechs-no-mundo-claudia-backes.pdf>. Acesso em 10.02.2019.

STARTUP GENOME. Global Startup Ecosystem Report 2017. Startup Ecosystem Lifecycle. 2018. Disponível em: < https://startupgenome.com/reports/startup-ecosystem-lifecycle-model-explained>. Acesso em: 05.02.2019.

STARTUP GENOME. Global Startup Ecosystem Report 2018. 2019. Disponível em: $<$ https://startupgenome.com/reports/state-of-startup-ecosystems>. Acesso em: 06.02.2019.

THE WORLD BANK. Doing Business 2017. Training for Reform. 14th. 2017. Disponível em: $<$ https://www.doingbusiness.org/content/dam/doingBusiness/media/Annual-Reports/English/DB17Report.pdf>. Acesso em: 10.02.2019.

THE WORLD BANK. Doing Business 2019. Training for Reform. 16th. 2019. Disponível em: $<$ https://www.doingbusiness.org/content/dam/doingBusiness/media/Annual-Reports/English/DB19Report.pdf>. Acesso em: 10.02.2019.

VIEIRA, Lucas Bezerra. Direito para startups: manual jurídico para empreendedores. Natal, RN: EdiçãSo do autor, 2017. 